\title{
Semiótica, planeación y estrategia publicitaria: aproximaciones desde la pragmática peirceana
}

\author{
Semiotics, planning and advertising strategy: \\ approaches from peircean pragmatic
}

Semiótica, planejamento e estratégia publicitária: aproximações desde a pragmática peirceana

Fecha de entrega: 15 de septiembre de 2014

Fecha de evaluación: 20 de noviembre de 2014

Fecha de aprobación: 15 de diciembre de 2014

\author{
Vladimir Sánchez Riaño* \\ Jairo Roberto Sojo Gómez** \\ Juan José Arango Correa ${ }^{* * *}$
}

\section{Resumen}

El presente artículo es el resultado de un proceso de investigación originado en la Maestría en Publicidad de la UTL (Universidad Jorge Tadeo Lozano), en la línea de Semiótica Publicitaria, dirigida por el profesor Vladimir Sánchez, quien en su seminario (del mismo nombre),

* Vladimir Sánchez es Magister en Semiótica (UJTL), docente Universidad Jorge Tadeo Lozano. Contacto: vladimir.sanchez@utadeo.edu.co

* Jairo Sojo es Especialista en Psicología del Consumidor (Fundación Konrad Lorenz). Contacto: jairo. sojo@utadeo.edu.co

*** Juan Arango es Diseñador Industrial (PUJ). Contacto: juan.arango@utadeo.edu.co Nomenclatura y división de las relaciones triádicas hasta donde están determinadas correspondiente a MS 540. Ver bibliografía completa al final del artículo. 
ha venido construyendo un equipo de trabajo con los maestrantes en torno a la aplicabilidad de algunos de los postulados de la pragmática de Charles Sanders Peirce al campo publicitario. Los maestrantes Jairo Sojo y Juan José Arango (profesores del programa de pregrado en Publicidad), adelantaron algunas hipótesis sobre el trabajo del profesor Sánchez, y, gracias a ello, se propuso a la UJTL y a la Universidad Santo Tomás (desde el Doctorado en Filosofía), un proyecto interinstitucional de investigación titulado "Semiótica, planeación y estrategia publicitaria y de diseño. Proyecciones del Pragmatismo a la comunicación contemporánea”.

En el marco de la investigación anteriormente mencionada, surge el artículo que aquí se presenta, como un primer planteamiento de las hipótesis de investigación que dan origen a dicho proceso y que pueden esbozarse en tres grandes aspectos. El primero, unas consideraciones generales sobre el pragmatismo desde una perspectiva publicitaria con énfais en la regla de cualificación planteada por Peirce en 1903. El segundo, la propuesta de un modelo de análisis de piezas publicitarias desde la operacionilización de la regla de cualificación. El tercero una modelación para la planeación de estrategias publicitarias a través de la regla de cualificación aplicada al cruce de los interpretantes ${ }^{1}$ ontológicos y los interpretantes modales.

Palabras clave: semiótica, planeación, estrategia, publicidad, pragmática.

\section{Abstract}

The following paper is the result of a research process originated in the Advertising Semiotics of the Masters in Advertising at Jorge Tadeo Lozano University, taught by Professor Vladimir Sánchez (associate professor of the Advertising Program at UTJL), who has built a team of Master's students in the field of Advertising Semiotics regarding the applicability of Charles Sanders Peirce pragmatic work in advertising.

1 Se entiende como el efecto producido en una mente tras la acción de un signo, por lo cual es a su vez un signo equivalente o más desarrollado. Así pues, el interpretante es un signo producido por otro signo, el cual puede producir otro interpretante, aunque no necesariamente. 
Master's students Jairo Sojo and Juan José Arango (both associate professors at the Advertising Program at UJTL) have speculated some hypothesis of professor Sánchez's work, which were the base for a inter-institutional research project between the Advertisng Master's program at UJTL and Santo Tomás University PHD in Philosophy "Semiotics, planning and strategy in Advertising and Design. Pragmatism proyections to contemporary communication".

This paper presents the initial hypothesis proposed in the above mentioned project, that give way to this process, and can be stated in three main aspects. First, general considerations of pragmatism from an advertising perspective, with an emphasis in Peirce's 1903 Qualification Rule. Second, to propose a model of analysis of advertising pieces through the Qualification Rule. Third a new model for planning advertising strategies, using the applied qualification to the intersections of ontological interpretants with modal interpretants.

Keywords: Semiotic, planning, strategic, advertising, pragmatic.

\section{Resumo}

O presente artigo é o resultado de um processo de pesquisa iniciado no mestrado em Publicidade da UJTL (Universidade Jorge Toledo Lozano), na linha de Semiótica Publicitária, dirigida pelo professor Vladimir Sánchez, o qual vem construindo uma equipe de trabalho com os mestrandos em torno da aplicabilidade de alguns dos postulados da pragmática de Charles Sanders Peirce ao campo publicitário. Os mestrandos Jairo Sojo e Juan José Arango (professores da graduação em Publicidade) apontam algumas hipóteses sobre o trabalho do professor Sánchez, e em decorrência foi proposta à UJTL e à Universidade Santo Tomás (ao doutorado em Filosofia), um projeto interinstitucional de pesquisa, intitulado "Semiótica, planejamento, estratégia publicitária e de desenho. Projeções do Pragmatismo à comunicação contemporânea”.

No marco da pesquisa anteriormente mencionada surge o artigo que aqui se apresenta, como uma primeira exposição das hipóteses de pesquisa que originaram este processo e que podem ser esboçados em três aspectos. O primeiro são considerações gerais sobre o pragmatismo desde uma perspectiva publicitária com ênfase na regra de qualificação, 
problematizada por Peirce, em 1903. O segundo é a proposta de um modelo de análise de peças publicitárias desde a operacionalização da regra de qualificação. O terceiro e último é a construção de um modelo para o planejamento de estratégias publicitárias através da regra de qualificação aplicada ao cruzamento entre os interpretantes ontológicos e os interpretantes modais.

Palavras-chave: Semiótica, planejamento, estratégia, publicidade, pragmática.

\section{Introducción}

... and after all, the only reader to whom I can be of any service at al lis the oner who will read what I writw and will carefully and critically reflect upon it. Him, and him alone, I am absolutely certain of benefitting, though he conclude that I am in the wrong from beginning to end (Peirce, 1913, p. 474) ${ }^{2}$.

Un examen menos primario del que se lleva a cabo en el mundo de lo cotidiano, devela la profundidad metafísica de la mayoría de las acciones que los seres humanos llevan a cabo, pero también, muestra la riqueza semántica y variabilidad pragmática de las palabras con las que nos expresamos. Desentrañar el sentido de las acciones, la manera como las nombramos y la forma en que intervenimos con nuevas acciones en el mundo que nos es dado, es tarea no solo del filósofo pragmático, sino del hombre de acción, que en el examen de lo cotidiano, encuentra la clave para intervenir la realidad que le es dada, pronosticando y planeando lo que realiza y previendo los resultados esperados.

En el supuesto pragmático anteriormente esbozado, se encuentra el origen y sentido de lo que aquí se postula. Los autores siguiendo el epígrafe con el cual se da inicio a esta introducción, partimos de la presunción de convertirnos en esos posibles lectores reflexivos y críticos previstos por Peirce, lectores de un texto como Nomenclatura y división de las relaciones triádicas hasta donde están determinadas, que consideramos es vertebral en la comprensión de la pragmática peirceana y en las posibilidades aplicativas de ella en el ejercicio publicitario. Así pues, se busca trascender la acepción

2 Correspondiente al MS 682, publicado en EP 2, 463-476. 
puramente fisiológica del acto de leer, para acceder a una fase comprensiva e interpretativa que sea el puente para la propuesta de modelaciones conceptuales aplicadas en el campo de la planeación y la estrategia publicitaria en el mundo contemporáneo.

Lo que el lector encontrará a continuación es un ejercicio propedéutico acerca de la apropiación, comprensión y proyección de algunos postulados de la pragmática peirceana al campo publicitario, para ello se desarrollarán tres aspectos metodológicamente enlazados. El primero unas consideraciones generales de carácter teórico conceptual que buscan dar cuenta de forma sucinta de los rudimentos teóricos del pragmatismo y de la regla de cualificación planteada por Peirce, el segundo una propuesta de análisis desde dicha regla, y el tercero una propuesta de planeación desde la regla de cualificación aplicada a la teoría de los interpretantes.

\section{El universo de lo posible: pragmatismo, relaciones triádicas y regla de cualificación}

Todo anuncio publicitario tiene como objetivo generar y movilizar representaciones, remisiones e interpretaciones ${ }^{3}$ deseables y favorables frente a bienes, productos, servicios, personas e ideologías. El proceso anteriormente descrito, así como su impacto en la comunicación contemporánea y su aporte en la construcción de los procesos culturales del mundo globalizado, es posible de ser analizado, interpretado e intervenido en forma propositiva a la luz de los avances que las ciencias sociales y humanas otorgan al campo publicitario. En el caso particular de este artículo, el punto de partida es el corpus teórico de la pragmática de Charles Sanders Peirce, desde la cual es posible comprender el proceso semeiósico ${ }^{4}$ que subyace a la manifestación de sentido en los mensajes publicitarios y en la publicidad misma como mensaje y texto socio-antropológico. Dicho proceso es entendido como un acto de

3 Al utilizar objetos, espacios y universos de sentido, el autor del mensaje publicitario al mismo tiempo (y quizá no muy conscientemente), se vale de procesos de representación, de remisión y de interpretación para generar respuestas posibles, reales o ideales frente a bienes, productos, servicios e ideologías. En efecto, un anuncio de cerveza -por ejemplo-, representa a la cerveza, esto es, está en lugar de ella; pero también remite a un posible contenido (mental) particular de cerveza, por ejemplo a su grado de suavidad, a su sabor o a su textura; igualmente se da interpretación ya que el anuncio implica que hubo un productor ideal del mismo, que anticipó un intérprete con la capacidad de actualizar la interpretabilidad o interpretación posible del signo.

4 Entiéndase aquí por semeiósico, la relación entre el signo, el objeto al que representa y el interpretante que media. 
producción de sentido, que se da gracias a "la acción, o influencia, que es, o implica, una cooperación de tres sujetos, a saber un signo, su objeto y su interpretante" (CP $5.484)^{5}$. Para el caso de este artículo, se entiende como el resultado de la relación entre el representamen, el objeto representado y el interpretante que permite comprender la representación, construir una posible significación, evaluar sus efectos prácticos en los individuos, las sociedades y la cultura y proponer una modelación para la estrategia y la planeación en publicidad.

\section{Pragmatismo}

Los orígenes más antiguos de lo que posteriormente se denominaría el pragmatismo, pueden rastrearse en la Grecia antigua con Hermógenes, para quien el significado de una palabra lo determina su uso y no la naturaleza de esta: "la naturaleza no ha dado nombre a ninguna cosa: todos los nombres tienen su origen en la ley y el uso; y son obra de los que tienen el hábito de emplearlos" (Platón, 1970, p. 169) ${ }^{6}$. Sin embargo el surgimiento y desarrollo del pragmatismo está directamente relacionado con el movimiento filosófico norteamericano de fin del siglo XIX denominado The Metaphysical Club, conformado por Charles Sanders Peirce, William James, Chauncey Wright, Nicholas St. John Green, Oliver Wendell Holmes, Joseph Bangs Warner, John Fiske y Francis Ellingwood Abbot. Este movimiento en términos generales considera que los efectos prácticos de una teoría se constituyen en el único criterio válido para juzgar su verdad.

Más adelante el propio Peirce prefiere tomar distancia de los demás pragmatistas y decide utilizar Pragmaticismo. En efecto, en su artículo de 1905: "Qué es el Pragmatismo" propone el nacimiento de dicho término para diferenciarlo del uso común y ligero que se venía usando y que lo alejaba de su idea original:

...Pero en la actualidad se empieza a encontrar la palabra ocasionalmente en los periódicos literarios, donde se abusa de ella del modo impío que las palabras deben esperar cuando caen en las garras literarias. (...) De modo que, el escritor, (...) siente que (...) para servir al preciso propósito de expresar la definición

5 Léase Collected Papers. El primer número antecedido de punto hace referencia al volumen y los siguientes a los parágrafos en los que se desarrolla el volumen.

6 Citado por César González Ochoa en imagen y sentido, p. 23. Ver bibliografía completa al final de este trabajo. 
original, tiene el gusto de anunciar el nacimiento de la palabra "pragmaticismo", que es lo suficientemente fea para estar a salvo de secuestradores (CP 5.414).

El Pragmaticismo en Peirce puede entenderse como una especie de teoría del significado, y sus primeras manifestaciones explícitas aparecen en 1878 en el artículo denominado "Cómo esclarecer nuestras ideas", allí plantea que la realidad se nos impone de forma explícita y a partir de una crítica a los postulados de la duda metódica de Descartes, plantea que dado que la claridad no provee un contenido diáfano porque la claridad está considerada como el conocimiento de las cosas cuando están frente a nosotros, es decir la familiaridad con la idea: "una idea clara se define como aquella captada de manera tal que se la reconoce dondequiera que uno la encuentra, sin que se la confunda con ninguna otra. Se dice que es oscura si no alcanza esta claridad (CP 5.389) ${ }^{7}$.

De esta forma Peirce considera poco relevante la claridad como criterio de validez de una idea por su simple familiaridad con ella. En este sentido es posible que una idea me sea clara, es decir familiar, pero ello no asegura que sea verdadera: "supongo, sin embargo, que cuando los lógicos hablan de "claridad" lo que significan no es más que una tal familiaridad con una idea, ya que consideran de tan poco mérito esta cualidad que necesita complementarse con otra que llaman distintividad" (CP 5.389).

El hecho de que una idea sea distinta implica que se pueda distinguir de otra y esto se da en Descartes por la definición: "de manera que, según ellos, captamos una idea de modo distinto cuando podemos dar una definición precisa de la misma en términos abstractos" (CP 5.390). Como se ve, la distintividad no da la posibilidad de avanzar en el conocimiento, porque se queda solamente en lo formal, en la definición, sin una conexión con la experiencia de la realidad. Por lo anterior, dice Peirce, se hace necesaria la creencia. La creencia al tener una conexión directa con la acción, permite actuar y se convierte en una regla para la acción:

¿Y qué es, pues, la creencia? Es la semicadencia que cierra una frase musical en la sinfonía de nuestra vida intelectual. Hemos visto que tiene justamente tres propiedades: primero, es algo de lo que nos percatamos; segundo, apacigua la irritación de la duda, y, tercero, involucra el asentamiento de una regla de acción en nuestra

7 Publicado parcialmente en W 3:257-276, corresponde a la serie Popular Science Monthly (enero de 1887). 
naturaleza, o dicho brevemente, de un hábito. “Al apaciguar la irritación de la duda, que es el motivo del pensar, el pensamiento se relaja, reposando por un momento, una vez alcanzada la creencia” (CP 5.397).

Así, desde la perspectiva peircista es claro que en la vida real, al surgir dudas reales que afectan la creencia, se hace necesario fijar una nueva creencia que sirva como guía para la acción y se instaure como un nuevo hábito. Así las cosas, la única función del pensamiento es generar hábitos de sensación, acción y de pensamiento o hábitos racionales ${ }^{8}$.

En términos comunicativos, el pragmaticismo permite comprender y prever la manera en que se pueden generar las dudas frente a la experiencia real, de tal manera que frente a esas dudas pueda generarse una comunicación que permita encarnar una nueva creencia que dispare unas nuevas reglas para la acción, es decir hábitos encarnados. El anclaje en la realidad es definitivo en el pragmaticismo peirceano y resulta de primer orden tanto en la comunicación como en los procesos cognitivos que permiten fijar nuestras creencias. Dice la máxima pragmática: “considérese qué efectos, que pudieran tener concebiblemente repercusiones prácticas, concebimos que tiene el objeto de nuestra concepción. Entonces nuestra concepción de estos

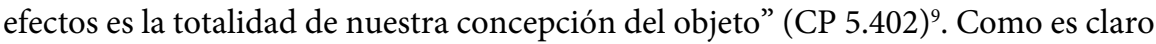
en la máxima pragmática, el pragmaticismo peirceano va más allá de la definición mental, ya que se advierte que el significado de algo devine de sus efectos prácticos posibles y amplía la posibilidad de conocer algo más allá de los objetos y de una colección de datos.

\section{Las relaciones triádicas y la regla de cualificación}

La intencionalidad de generar una respuesta favorable en la mente del intérprete frente al bien, producto, servicio o ideología al que se refiere el signo, o en términos peircistas, el interpretante inmediato (respuesta posible) que ha sido determinado por el objeto inmediato (el objeto tal y como es representado en el signo), determinado a su vez por un objeto dinámico (el objeto de la realidad), se constituye en la respuesta determinada por el representamen, objeto diseñado o pieza en consideración. Este

8 Aqui se plantea una hipótesis interpretativa a la espera de mayor desarrollo que se desprende de la lógica de las categorías de primeridad, segundidad y terceridad.

9 Publicado parcialmente en EP (The Essential Peirce) 1.109-41, y W (Wrintings) 3.242-76 y 338-74. 
proceso de semiosis, se instaura gracias a la intencionalidad o teleología expresada en cualquier signo y que es posible de inferir por vía de la interpretabilidad, entendida como la extracción de toda la cantidad posible y legítimamente dable de información en el signo. El desentrañamiento de la teleología del mensaje resulta siendo de primer orden, si nos atenemos a lo planteado por el mismo Peirce:

La importancia del asunto para el pragmatismo es obvia, pues si el significado de un símbolo consiste en "cómo" podría hacernos actuar, es evidente que ese "cómo" no puede referirse a la descripción de los movimientos mecánicos que podría causar, sino que debe referirse a una descripción de la acción como teniendo este o aquel fin (CP 5.135) ${ }^{10}$.

Por ello el análisis del representamen y de la respuesta justificada posible (interpretante inmediato) permite inferir la hipótesis acerca del propósito al que busca dar cumplimiento el representamen, y asimismo valorar si la composición misma de dicho representamen cumple con el propósito inferible en él. En este sentido el representamen (más concretamente el objeto inmediato ${ }^{11}$ ) es concebido como un medio para alcanzar el propósito buscado por un agente, que en este caso es el "hacedor" de la pieza.

Así, dado que el signo se encuentra por algo pero en algún aspecto, el representamen da cuenta de un objeto inmediato, el cual representa algún aspecto, o mejor, el aspecto bajo el que se representa al objeto dinámico y que se constituye así en el vehículo que moviliza el propósito que se debe evidenciar en el interpretante inmediato, en el interpretante dinámico y en el interpretante final. Es decir, si el signo está correctamente expresado, deberá obtenerse una respuesta posible que puede actualizarse en una respuesta real y que puede desarrollarse en una respuesta ideal cuyo contenido da cumplimiento al propósito, estableciendo una relación entre el interpretante y el objeto inmediato, de la misma naturaleza que la que establece el representamen con este mismo objeto.

10 Correspondiente a la quinta lección de las "Harvard Lectures" del 30 de abril de 1903. MS 312. Publicado en CP 5.120-150 y en HL 205-220. Dejada sin título por Peirce, ha sido nombrada en español como: "Los tres géneros de Bondad" o "Las tres ciencias normativas". Se usa la traducción de Darin McNabb, con revisión de Sara Barrena, Publicada Por el Fondo de Cultura Económica bajo el título Obra Filosófica reunida. Ver bibliografía completa al final de este trabajo.

11 Objeto en cuanto representado en el signo (L 224). 
En 1903 Peirce amplía la noción de signo ${ }^{12}$ y plantea su división de las relaciones triádicas de comparación, de actuación y de pensamiento. En las primeras sostiene que su naturaleza es la de las posibilidades y por ello se relacionan con la primeridad. En las segundas su naturaleza es la de los hechos reales, lo que las relaciona con la segundidad. En las terceras su naturaleza es la de las leyes, por lo tanto, se relacionan con la terceridad.

Dice Peirce que en cualquier relación triádica se debe distinguir entre el primer, segundo y tercer correlato. El primer correlato (el signo) se encuentra en el ámbito de la primeridad pues es pura posibilidad, el segundo correlato (el objeto) se encuentra en el ámbito de la segundidad ya que es la realidad, y el tercer correlato (el interpretante), se encuentra en el ámbito de la terceridad, pues es ley. Así, "las relaciones triádicas por tricotomía son divisibles de tres modos, según sea el primer, segundo o tercer correlato", esto es: "una mera posibilidad, un existente real o una ley" (CP 2.238).

Siguiendo estas relaciones Peirce establece que:

Los signos pueden dividirse de acuerdo con tres tricotomías, la primera teniendo en cuenta el signo en sí mismo. La segunda teniendo en cuenta la relación con su objeto y la tercera según la manera como su interpretante lo represente como posibilidad, hecho o razón (CP 2.243).

Según la primera división, los signos pueden ser cualidades, cosas/acontecimientos o leyes/ tipos:

[...] un Signo puede clasificarse en Cualisigno, Sinsigno o Legisigno.

Un Cualisigno es una cualidad que es un Signo. De hecho, no puede actuar como signo hasta que sea encarnado $[\ldots]$.

Un Sinsigno [...] es una cosa o acontecimiento de existencia real, la cual es un signo $[\ldots]$.

Un Legisigno es una ley [...] Todo signo convencional es un legisigno. No es un único objeto sino un tipo general. [...] Todo legisigno adquiere significación

12 En el Manuscrito 540, publicado en CP 2.233-72. 
por medio de un caso de su aplicación, que puede denominarse una Réplica suya (CP 2.244-46).

Aunque el cualisigno es una cualidad, para ser observable es necesario que esté encarnado, por lo cual es observable gracias a un sinsigno. El sinsigno es algo real que depende de circunstancias espaciales y temporales, es una cosa o acontecimiento que tiene una ocurrencia singular. El legisigno es una ley que es convencional y general, es un tipo que se actualiza en ocurrencias que son sinsignos, por lo que una réplica del legisigno es a su vez un sinsigno que se entiende como ocurrencia del legisigno.

En la segunda tricotomía los signos establecen relaciones de parecido, acción/reacción o convencionalidad ${ }^{13}$ :

Un Ícono [...] se refiere al Objeto que denota [...] en virtud de sus propios caracteres, los cuales posee independientemente de que dicho Objeto exista en realidad o no. [...] Cualquier cosa, ya sea una cualidad, un individuo existente o una ley, es un Ícono de algo en cuanto se parece a esa cosa y es utilizado como signo de ella.

Un Índice [...] se refiere al Objeto que denota en virtud de que es afectado realmente por ese Objeto. [...] En cuanto que el Índice es afectado por el Objeto, es necesario que tenga alguna Cualidad en común con el mismo. [...] Lo que lo hace signo [...] es [...] la modificación real que el Objeto le causa.

Un Símbolo [...] se refiere al Objeto que denota en virtud de una ley. [...] Por lo tanto, es en sí mismo un tipo general o ley, es decir, un Legisigno. Como tal, actúa a través de una Réplica. No solo es el general sino que el Objeto al que se refiere también es de naturaleza general (CP 2.247-49).

En esta segunda tricotomía el quid clasificatorio está en la relación del signo con su objeto. En cuanto al ícono, este mantiene una relación de semejanza, es ícono siendo una cualidad (cualisigno), un existente (sinsigno) o una ley (legisigno) en la medida en que se parece a la cosa denotada. En cuanto al índice, este mantiene con su objeto una relación de conexión dinámica (es afectado por el objeto), por tanto lo que lo hace índice es la modificación real que el objeto le causa. El símbolo mantiene con

13 Esta relación fue trabajada más arriba a partir de las tres clases de signos enunciadas por Peirce en el manuscrito 404, titulado "¿Qué es un signo?", publicado parcialmente en CP 2.281, 285 y 297-302. 
su objeto una relación de representación en virtud de una ley o convención, por lo tanto el símbolo es un signo general o legisigno.

En la tercera tricotomía se considera la manera como el interpretante representa al signo, lo cual puede ser como signo de posibilidad, como signo de existencia real o como signo de ley:

Un Rhema es un Signo que, para su Interpretante, es un Signo de posibilidad cualitativa, es decir que es entendido como representando tal o cual tipo de Objeto posible [...].

Un Signo Dicente es un Signo que, para su Interpretante, es un Signo de existencia real $[\ldots]$.

Un Argumento es un Signo que, para su Interpretante, es un Signo de ley [...] un Argumento es un signo entendido como representación de su Objeto en su carácter de Signo (CP 2.250-52).

El Rhema es para su interpretante un signo de posibilidad cualitativa entendido como representando tal o cual objeto posible, su interpretante lo "interpreta" como un signo de posibilidad. Por su parte el Signo Dicente es para su interpretante un signo de existencia real, tiene que poseer como parte de él un Rhema, su interpretante lo "interpreta" como un signo de existencia real. El Argumento es para su interpretante un signo de ley, es decir debe ser un legisigno y su interpretante lo "interpreta" como un signo de ley.

A continuación se presenta una visión esquemática de la "Nomenclatura y divisiones de las relaciones triádicas hasta donde están determinadas” (1903), de donde se extrae la presentación anterior, en la cual se evidencia que estas tres tricotomías arrojan como resultado 10 clases de signos que a su vez se expresan en lo que aquí hemos denominado el cuadro de Cualificación, en donde el movimiento siempre debe ser en la misma línea o en forma ascendente y nunca descendente: 


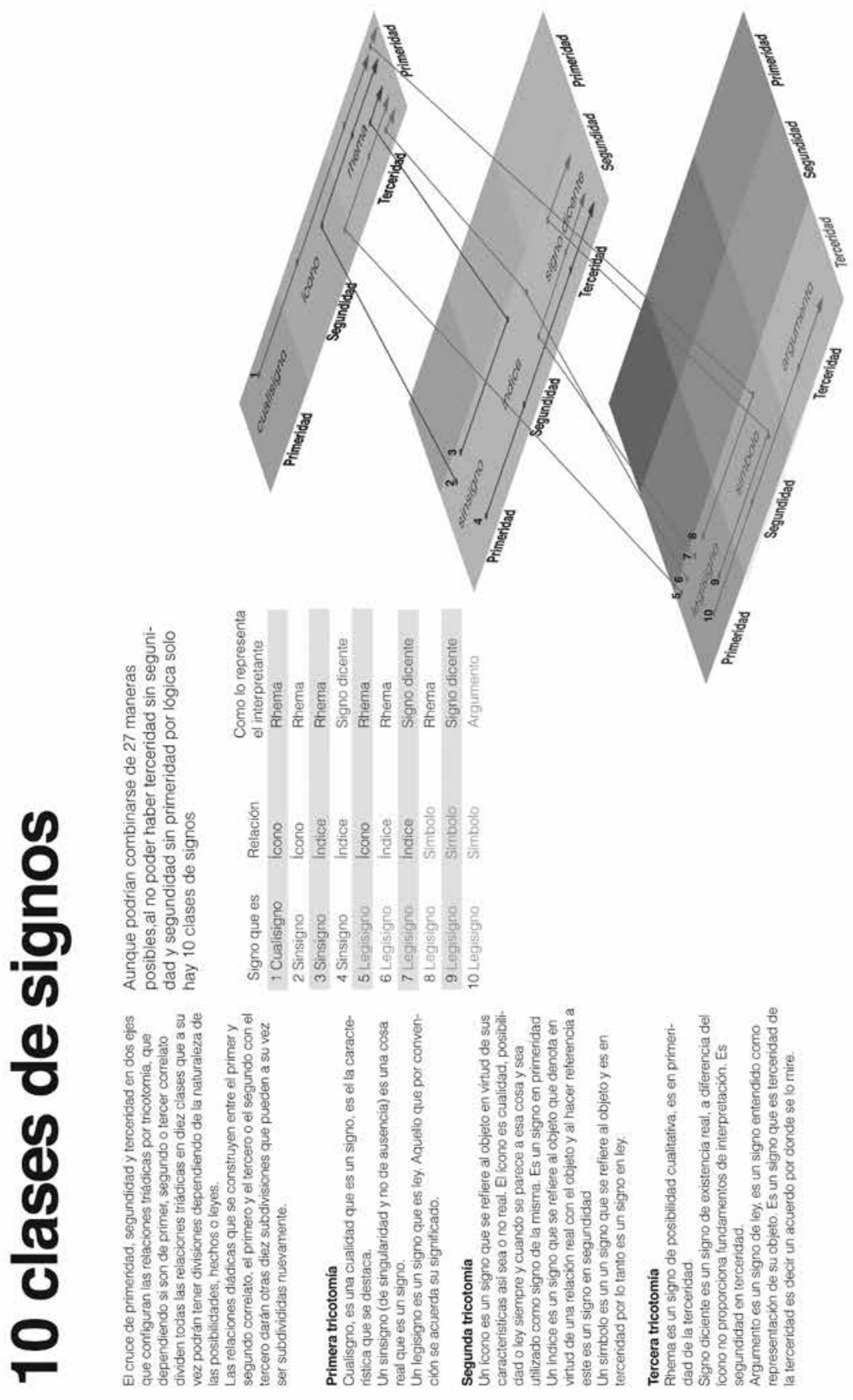




\section{El universo de los hechos: modelo de análisis y evaluación del sentido publicitario}

La responsabilidad del éxito de la comunicación publicitaria recae exclusivamente en el generador del mensaje. El espectador, casi nunca está dispuesto a recibir la publicidad porque no la espera, no la busca y seguramente no la desea, se la encuentra de manera abrupta, entre un programa televisivo, entre un artículo en una revista, entre la arquitectura de la ciudad. Esta epifanía del mensaje publicitario le exige al generador de las campañas y de las piezas que las componen, no solo una claridad comunicativa en lo que se quiere movilizar, sino también el reto de generar interés, atención y respuesta en su destinatario (target) y para ello solo tiene unos pocos segundos antes de que se cambie el canal, se pase la página o se mire hacia el otro lado de una valla.

El resultado del ejercicio publicitario, es decir, una pieza que genere en el espectador la respuesta anticipada por el productor, es en todos los casos una "educated guess", una apuesta educada, debido a que siempre podrán existir respuestas múltiples por parte del espectador. Es decir, resolver un problema comunicativo desde lenguajes no estructurados como es el lenguaje visual permitirá siempre una libre interpretación, como dice Brandt (2006) en el sentido que, "aunque el mensaje tiene una base que es común a todo aquel que se enfrenta a la pieza, cada individuo terminará por construir también una parte del sentido desde su bagaje personal”. Por esta razón, podría decirse que existe una subjetividad inherente al diseño publicitario, pero esta puede ser mermada a partir de la aplicación de una serie de herramientas que validen o comprueben la propuesta creativa.

Existe la creencia de que el creativo en una agencia de publicidad puede imaginar una pauta desde sus propios referentes, sin tener en cuenta al espectador casi como un artista crea una obra, pero la labor del creativo en este caso no es expresar un sentimiento propio sino el servir de intérprete entre la marca y el usuario, por lo tanto la manera en que construye el mensaje debe mediar entre las dos partes, teniendo la certeza de que el lugar que interesa es aquel donde se construye el significado, es decir, los referentes a usar por el creativo no están dentro de los que él mismo tiene, sino que un diseño publicitario bien construido deberá partir de los referentes del espectador y el contexto donde este se sitúa. Por esta razón dentro del proceso de diseño deben existir métodos de investigación y creación que le permitan al creativo producir desde el otro. 
Si como se plantea inicialmente el éxito de una pieza está en que la respuesta que se dé en el espectador, sea la proyectada por el creativo (diseñador), entonces una herramienta que permita validar o comprobar que los referentes utilizados sean los adecuados, será de gran utilidad en el ejercicio publicitario. Así las cosas, este tipo de herramientas y modelos de análisis permiten eliminar el nivel de subjetividad, en un intento por reducir el margen de error en la comunicación. Dado que la interpretación se dará a partir del bagaje o carga semiósica del espectador, toda interpretación del mensaje es válida, si esta no corresponde con la intención original del emisor evidenciará un problema tanto de investigación, como de construcción de la propuesta signinica o pieza publicitaria.

En una comunicación como la que se efectúa en la publicidad, en la cual, el receptor del mensaje no puede comunicarse por el mismo medio o canal con el emisor para la retroalimentación, sino que se da a través de respuestas posibles (memorabilidad y recordación), reales (decisión de compra y compra efectiva) o ideales (generación de afecto y fidelidad con la marca), se hace necesario un método o modelo que pueda prever con cierto nivel de seguridad las respuestas posibles (primeridad), reales (segundidad), o ideales (terceridad). En este orden de idas, la validación de la completud del mensaje publicitario debe ser entonces un hecho medible, el cual se puede efectuar a partir de la aplicación de la herramienta propuesta por Sánchez (2011).

Así pues, con una evaluación de la forma en que están construidos los signos, se puede advertir si una propuesta de campaña o de pieza publicitaria, tiene posibilidades de ser exitosa, es decir, si cumple con la finalidad de la campaña (en primeridad, segundidad o terceridad), y si los elementos de representación están correctamente construidos para que la audiencia los complete. Es por esto, que dicha herramienta se convierte en un aliado del proceso creativo publicitario, reduciendo la incertidumbre y proveyendo al publicista de una metodología sofisticada para analizar y evaluar sus productos comunicativos. En particular hay un lugar de especial atención para evaluar si un signo está bien construido, y es cuando goza (entre otras cosas), de un equilibrio entre aquello que representa y aquello que se interpreta, es decir, debe existir una misma relación entre el representamen y el objeto dinámico ${ }^{14}$ que entre el objeto dinámico y el interpretante.

14 El objeto real al cual se refiere la pieza o campaña. 
Cuando la respuesta en la mente del interprete (interpretante) no coincide con la intencionalidad buscada con el representamen, entonces el signo falla. De ahí que en el proceso creativo, la correcta identificación de la cualidad que se quiere representar y los elementos que constituyen el representamen, sea crucial, para que en la mente de aquel que interpreta (interprete) se pueda completar la misma relación. Desde esta perspectiva, se puede pensar que la misma relación en el uso del signo es un acto colaborativo inconsciente, que puede ser previsto a partir del análisis y evaluación de un signo a través de la herramienta propuesta por Sánchez "Modelo de análisis y evaluación desde la perspectiva semiótica de Charles Sanders Peirce” (Sánchez, 2011). En publicidad esta herramienta es un arma altamente sofisticada, en particular para la planeación publicitaria para proponer ejes conceptuales de realización de piezas y al mismo tiempo evaluar si el grupo creativo realizó la construcción de la campaña utilizando los signos correctos, en función de la respuesta esperada.

Haciendo una analogía con la geometría, la estructura tríadica que propone Peirce del signo se puede visualizar como un triángulo, y el que exista una correspondencia entre sus lados y pueda verse como un triángulo isósceles. Como muestra la siguiente figura solo el triángulo del centro tiene las mismas características entre sus lados, lo que le otorga la misma carga a todos los componentes del signo:
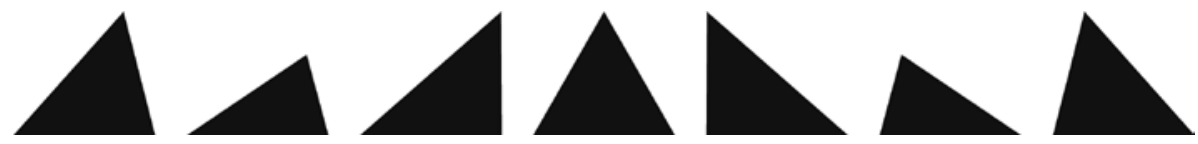

Podría decirse entonces, que la evaluación de la misma relación de un signo, se puede visualizar al hacer una graficación para identificar si existen tensiones o equilibrios dentro del signo, y tomar medidas rápidamente para corregir los problemas que se estén presentando, permitiendo comprender a partir de la analogía, si las cargas en los componentes del signo están siendo equivalentes:

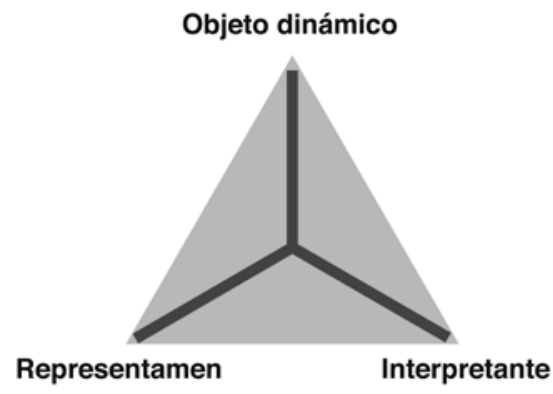


Cualquier desviación que lleve al signo a salirse de una estructura de la misma relación, hará que el signo no se pueda interpretar de manera correcta y que la información se pierda o resulte incompleta. Otra forma de representar la delicadeza del asunto sería voltear la estructura, licencia gráfica dada para la construcción de una metáfora de balanza en la cual se puede revisar el peso de representamen y representado y que sirve para demostrar la importancia del equilibrio de las partes del signo, por lo que el juicio de valor sobre el signo se podría visualizar de la siguiente manera:

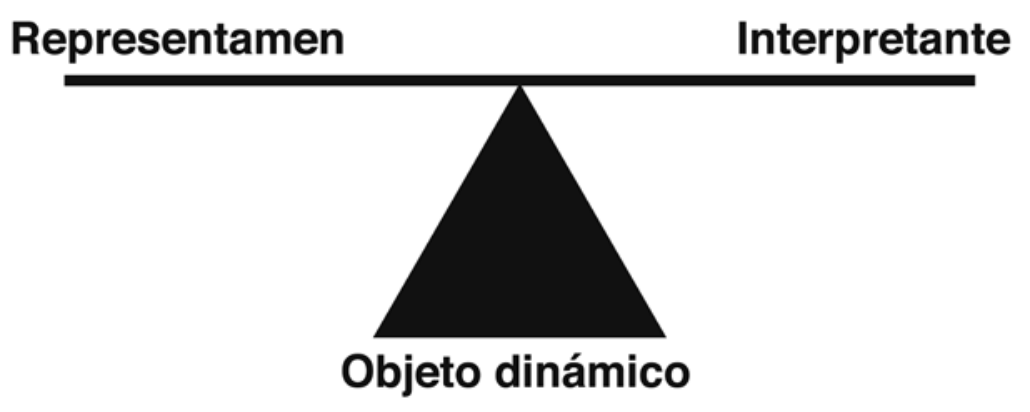

De modo que la misma relación de un signo se torna en un problema de equilibrio. Y atención, este es la parte del acto que lleva redobles, la responsabilidad de la misma relación recae en quien lo crea, no en quien lo interpreta. Es decir, si la campaña falla, fallará desde la agencia, el productor del mensaje, ya que no existe excusa revisando el modelo para que una campaña falle por el lado de la audiencia.

Habiendo señalado la importancia de la misma relación, que es condición indispensable en el modelo planteado por Sánchez (2011), a continuación se presenta una visión sintética del modelo y posteriormente una modelación gráfica sobre el modelo aplicado al análisis de una pieza publicitaria de referencia "Nopikex". Sánchez plantea un modelo de análisis y una evaluación de piezas publicitarias compuestas por tres momentos:

El primer paso del modelo es el análisis y evaluación del tipo de signo que es, se busca que el analista identifique y evalúe si el signo es una cualidad, una cosa/acontecimiento o una ley/tipo, y hacer una descripción del mismo, para identificar si la pieza estudiada responde a una intención publicitaria en primeridad, en segundidad o en terceridad.

El segundo paso es el del análisis y evaluación de la relación que se establece en la pieza publicitaria. Aquí se identifica y evalúa si el signo en consideración establece 
relaciones de parecido, acción/reacción o convencionalidad. Igualmente se describe en las relaciones de parecido si se dan por imagen, diagrama o metáfora, en las de acción/reacción si se dan por índices o subíndices y en las de convencionalidad si se dan por símbolo singular o por símbolo abstracto. Posteriormente se hace un análisis sígnico en dos niveles, empezando por un nivel básico en el cual se describen los objetos $^{15} \mathrm{o}$ situaciones que han sido representados, seguido de un nivel perceptual en el que se describe la percepción de lo que allí se encuentra representado.

En el tercer paso se identifica y describe el tipo de respuesta o signo equivalente que se produce como signo de posibilidad, como signo de existencia o como signo de ley. Asimismo se hace un análisis del interpretante inmediato de forma relacional como interpretante de cualidad (inmediato emocional), de existencia (inmediato energético) o de convención (inmediato lógico), dependiendo del objeto que determina al signo y este (posiblemente) a la mente del intérprete. En tercer lugar se analiza la interpretabilidad o información extraíble del signo a partir de los diferentes representamina que genera para evaluar el cumplimiento del propósito al que da respuesta el signo.

Aplicación del modelo a una pieza publicitaria:

15 No en el sentido técnico en Peirce sino en el sentido en que lo presenta Groupe $\mu$ a partir de Maurice Reuchlin: "el objeto percibido es una construcción, un conjunto de informaciones seleccionadas y estructuradas en función de la experiencia anterior, de las necesidades y de las intenciones del organismo implicado activamente en una determinada situación" (Groupe $\mu, 1993$, p. 80). 

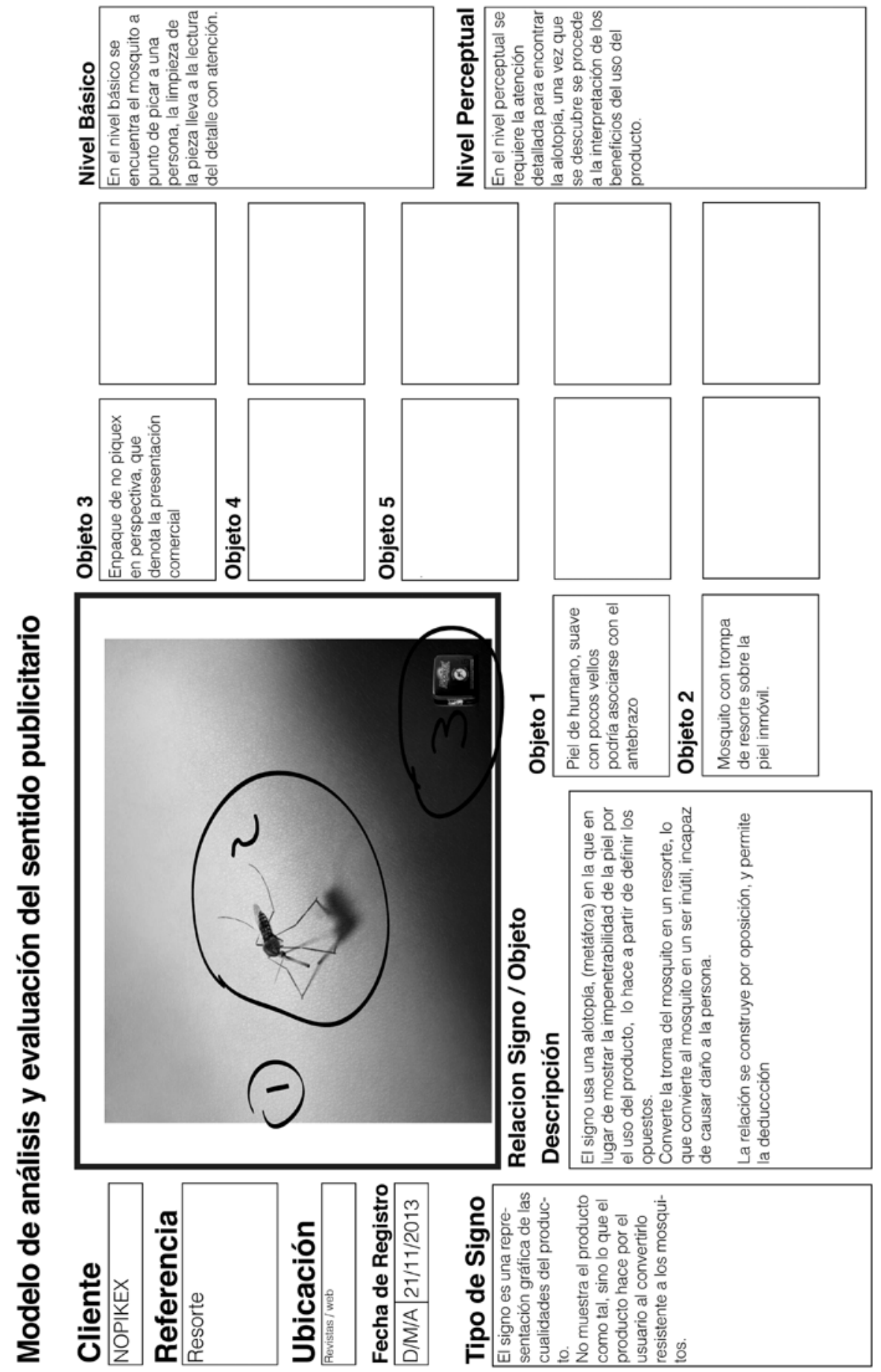

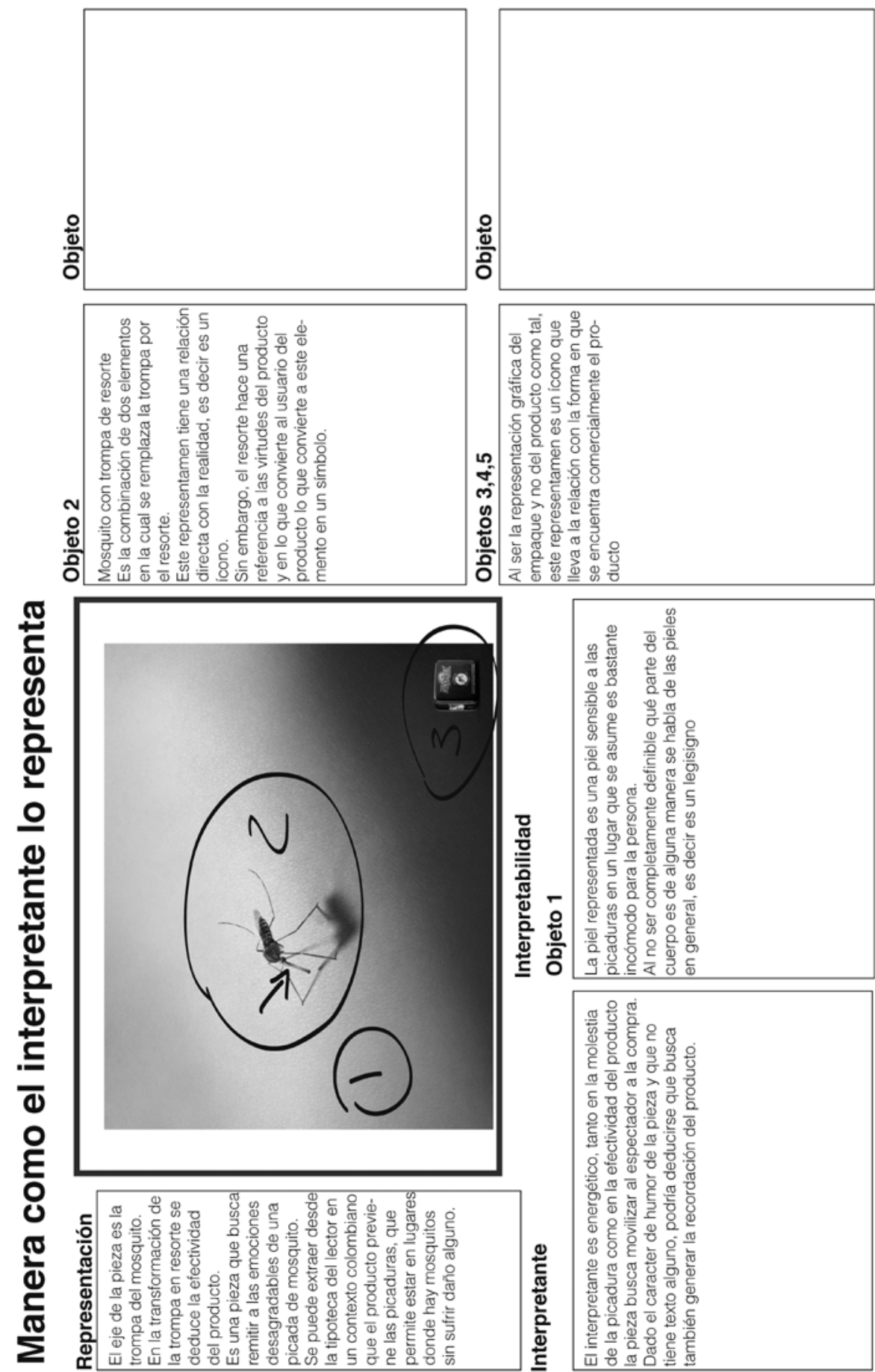

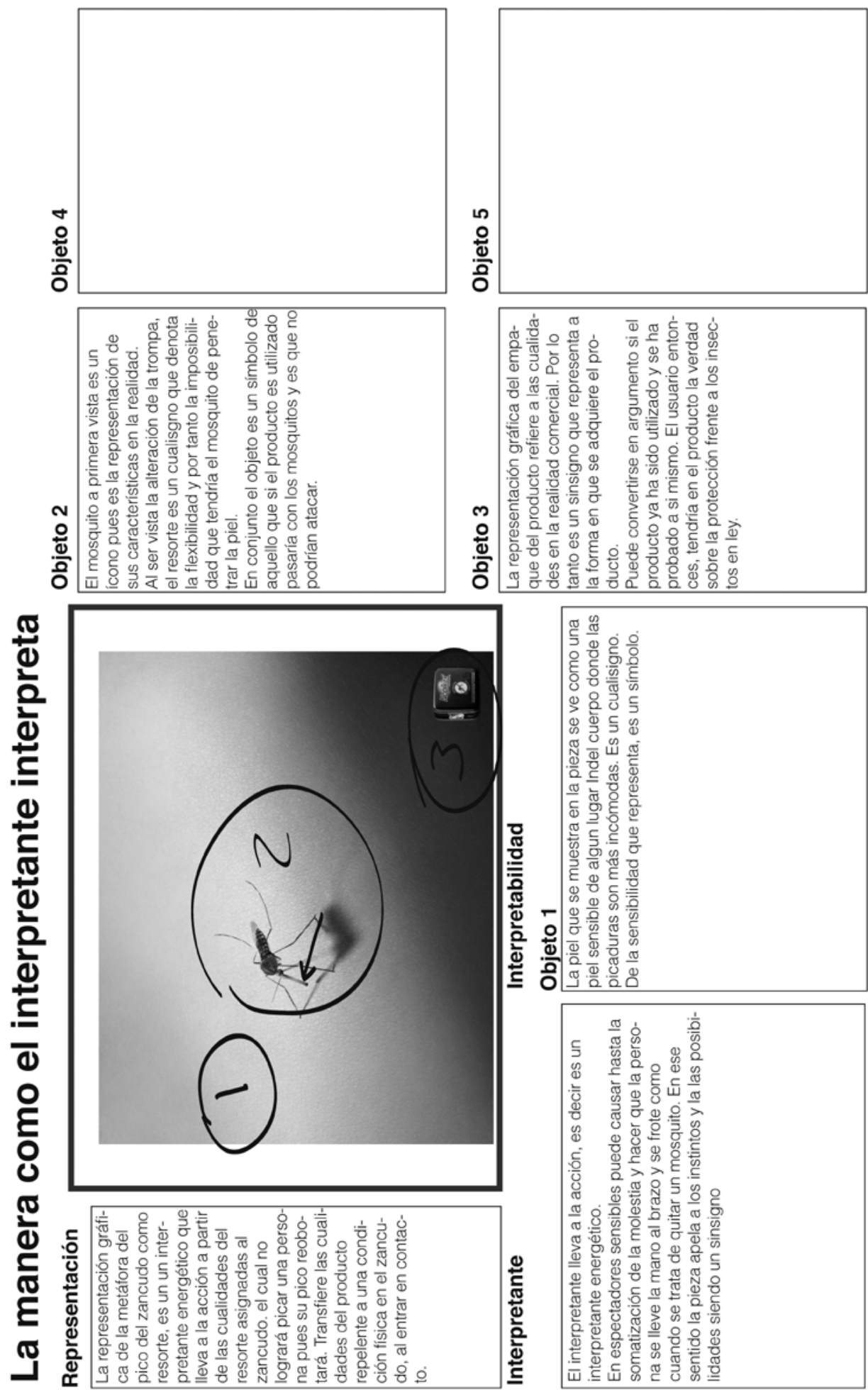

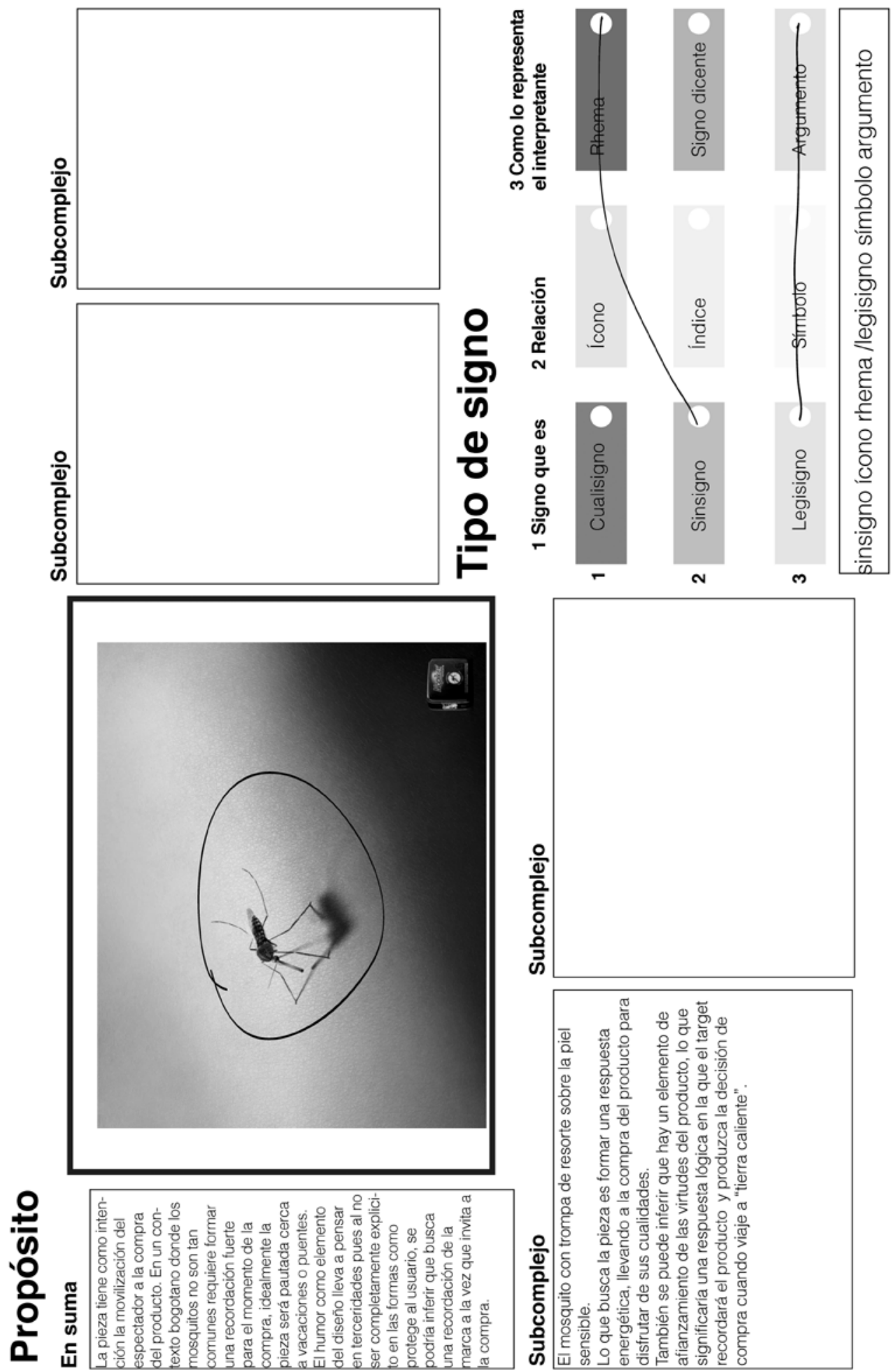

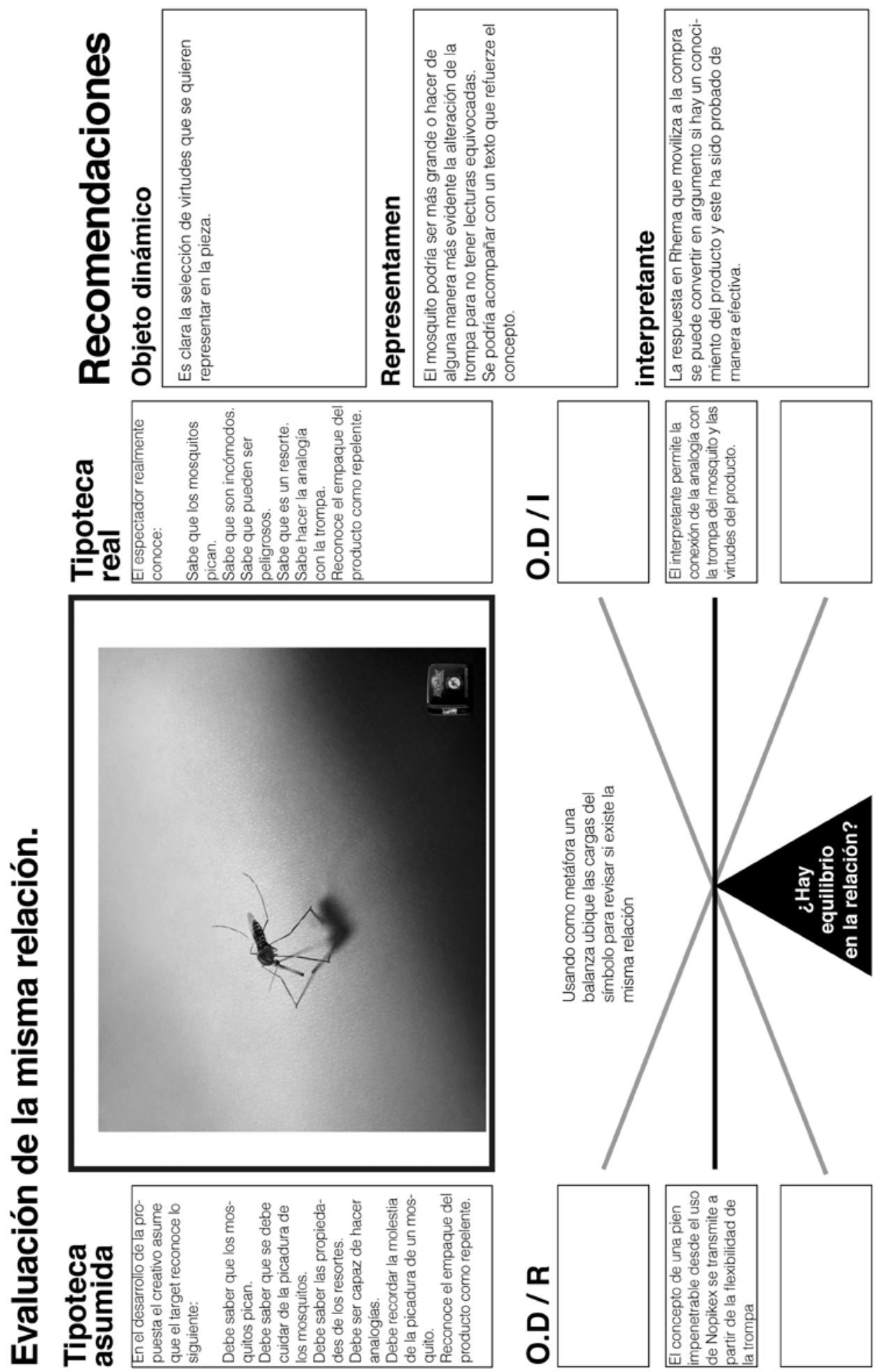
Este análisis permite evaluar la composición del signo o pieza publicitaria en consideración para prever la manera en que será representada en la mente del destinatario o target a quien va dirigido. Asimismo permite al equipo de planeación evaluar el trabajo del grupo creativo que construye la pieza y llevar a cabo recomendaciones. El modelo propuesto se encuentra en pura primeridad, como interpretante inmediato en la medida en que se evalúa la respuesta posible en la mente del intérprete. Según Sánchez (2011), el modelo puede ampliarse para hacer pruebas de concepto a través de Focus Group, en cuyo caso se estaría en el ámbito de la respuesta en segundidad, esto es en el interpretante dinámico. Asimismo se podría utilizar en análisis de arquitectura de marca (Branding) para evaluar la filiación y fidelización de los destinatarios con la marca en respuestas ideales (interpretante final).

\section{El universo de las leyes: modelo de planeación desde la construcción del sentido publicitario}

Esta tercera parte del artículo busca evaluar la aplicabilidad del modelo de Sánchez (2011) a piezas publicitarias, pero a partir de la propuesta de intersección de las dos tricotomías de interpretantes (Modales y Metafísicos), con el ánimo de explorar el aporte que dicha propuesta hace para la planeación y la estrategia publicitara. La hipótesis es que una vez analizada la pieza publicitaria con el modelo expuesto en el punto anterior de este artículo, se hace necesario ubicarla en el cuadro de la intersección de los interpretantes para recomendarle al cliente (anunciante), una estrategia publicitaria clara y acorde con la historia de vida de su producto, servicio o marca. La recomendación surgirá dependiendo de si la función publicitaria está basada en memorabilidad, decisión de compra o fidelización y si el efecto buscado es inmediato, dinámico o final y si dicho efecto tiene un carácter emocional, enérgico o lógico. La propuesta se basa en cruzar estas funciones para así encontrar el carácter publicitario y el efecto esperado en el propósito de la pieza publicitaria estudiada a continuación.

El anuncio de Aguardiente Cristal se identifica inicialmente por una caja tipográfica amarilla, en la cual dice "Excitante" en color amarillo, seguido por una fotografía con la figura de una mujer que se identifica como Amparo Grisales, quien tiene puesto un abrigo de piel color blanco que la cubre. Ella se encuentra sobre un sinfín blanco, y a su lado se puede identificar una botella de Aguardiente Cristal, y una copa con un líquido incoloro (que se asume es aguardiente) que está siendo sostenida por ella, con la intención de beberlo. En la parte inferior se encuentra el logo de la marca, con el slogan "Calidad que se exporta". 


\section{AVISO / DÉCADA DE 1980 / Licores}

Anunciante: Aguardiente Cristal

Referencia: Amparo Grisales

Ubicación: Revista Semana No. 346

Fecha de registro: agosto de 1988

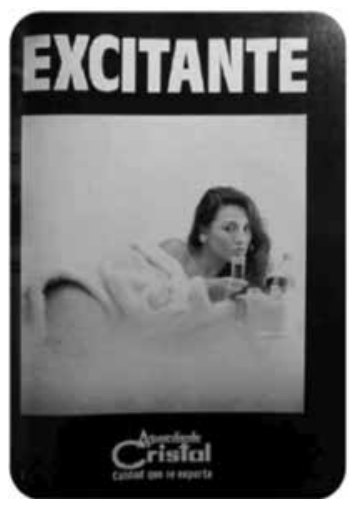

El signo establece una relación de convencionalidad con su objeto, ya que depende del conocimiento de que se trata del Aguardiente Cristal y de quién es Amparo Grisales. En este caso el objeto del signo es un aguardiente de "calidad de exportación". La convencionalidad se da gracias a la representación de lo excitante que es beber aguardiente, y que se reconoce por la caracterízación y convencionalización de Amparo Grisales como una mujer sexy.

Partiendo de la fotografía, y de la mujer que aparece en ella, se hace referencia sobre la importancia de dicha persona en la sociedad colombiana de aquella época, es decir, entendidas las normas de código y del objetivo de comunicación que es presentar el consumo de aguardiente como algo sensual, provocativo y legítimo.

La pieza en consideración es un argumento, ya que se evidencia representando un símbolo convencional asociado con su significado por el uso. Un signo que argumenta en cuanto informa sobre una experiencia $\mathrm{Al}$ momento de considerar el Aguardiente Cristal como algo tan excitante, como la sensualidad de Amparo Grisales.

El interpretante inmediato o respuesta posible que genera la pieza es una respuesta posible de carácter lógica, es decir es un interpretante inmediato lógico en el que se produce un hábito en el momento de consumir aguardiente. Así pues, el objeto inmediato tal como es representado en el signo, busca una respuesta posible de carácter emocional pero que desemboque en un carácter lógico, respuesta asociada con el hecho de que el intérprete tenga una información sobre el Aguardiente Cristal, como se indicó, a partir de la sensualidad de Amparo Grisales. A continuación se presenta una representación gráfica de lo anteriormente señalado. 


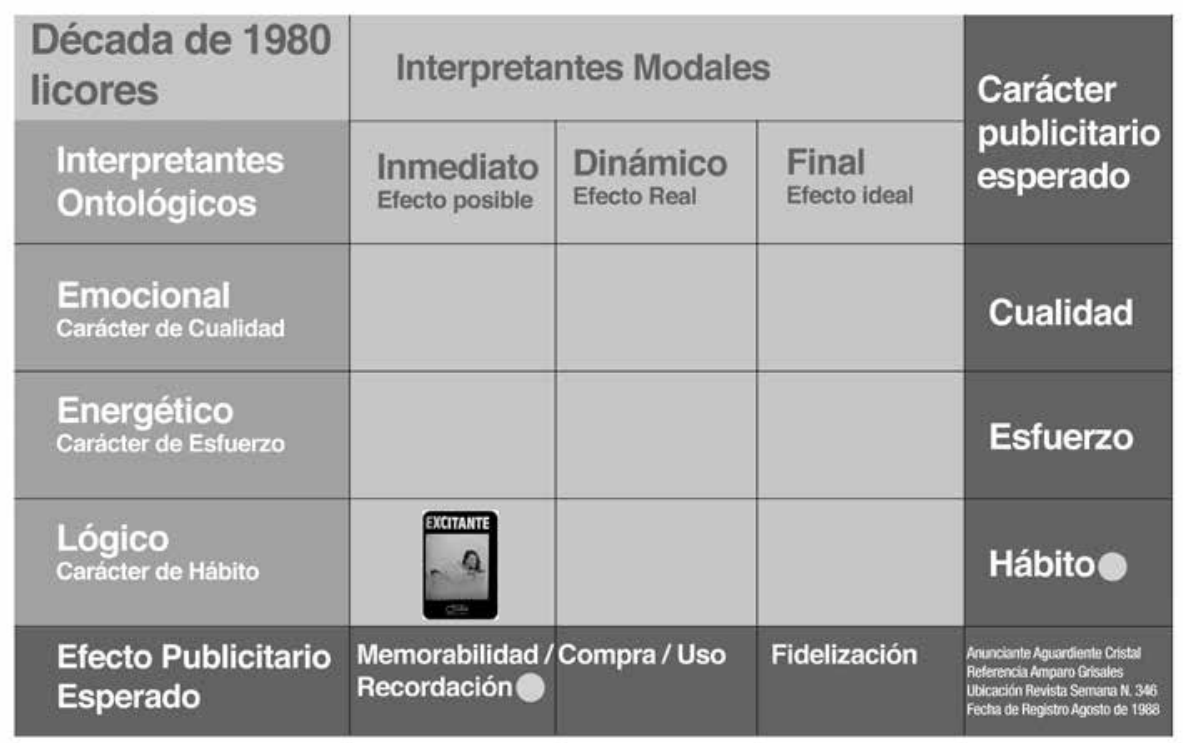

Según el propósito del aviso, poemos concluir que el aviso ref. Amparo Grisales del anunciante Aguardiente Cristal, según su interpretación Modal es Inmediato / Efecto posible Lógico (único efecto mental), siendo su efecto interpretación ontológica de carácter de hábito. Podemos concluir que lo único que busca el anunciante es una memorabilidad que genera hábito en el consumo siendo éste el carácter publicitario.

Con lo anterior, se puede plantear que de acuerdo con los intereses del cliente (anunciante), el estratega publicitario podrá, tras el estudio del propósito de las piezas publicitarias y con ellas de las campañas pautadas, llevar a cabo recomendaciones acerca de las acciones a seguir dependiendo del lugar en el que se encuentra la pieza o campaña en el cuadro de los interpretantes. Así, siguiendo la ley de cualificación se podrán identificar los pasos que se deben seguir en la planeación y la estrategia publicitaria que se recomiende al cliente (anunciante) por parte de la agencia publicitaria.

En el caso particular de la pieza analizada, el estratega tendrá seis posibilidades de movimientos estratégicos para la planeación publicitaria. Podrá analizar la posibilidad de proponer movimientos en cada uno de los seis espacios ubicados en la intersección de los interpretantes dinámicos y finales, con los interpretantes emocionales, energéticos y lógicos. Con estos movimientos, ya no solo se estaría en el ámbito de la primeridad en términos de los efectos posibles de la pieza, sino que se entraría a evaluar las acciones tácticas que se deben ejecutar en segundidad y en terceridad. En segundidad se estaría entrando en el ámbito de los interpretantes dinámicos que 
tienen que ver con la decisión de compra y la compra efectiva del producto, lo que en publicidad se denomina Call to Action. En terceridad se estaría entrando en el ámbito de los interpretantes finales que tienen que ver con la filiación de marca, que en publicidad se denomina Branding.

En ese orden de ideas, la publicidad puede estar en primeridad, segundidad o terceridad es decir, memorabilidad, decisión de compra o fidelización y si el efecto buscado es inmediato, dinámico o final y si dicho efecto tiene un carácter emocional, energético o lógico, reflejado en el carácter publicitario de cualidad, esfuerzo o hábito. La propuesta clara es que conociendo los propósitos de las piezas de comunicación, se pueden generar una serie de "cruces" que pueden ayudar a dar unas características especiales para reconocer las acciones tácticas a seguir:

\begin{tabular}{|c|c|}
\hline Efecto publicitario esperado & Carácter publicitario esperado \\
\hline Memorabilidad / Recordación & Cualidad \\
\hline Memorabilidad / Recordación & Esfuerzo \\
\hline Memorabilidad / Recordación & Hábito \\
\hline Compra / uso & Cualidad \\
\hline Compra / uso & Esfuerzo \\
\hline Compra / uso & Hábito \\
\hline Fidelización & Cualidad \\
\hline Fidelización & Esfuerzo \\
\hline Fidelización & Hábito \\
\hline
\end{tabular}

Este cruce arroja unas consecuencias muy claras que permiten clarificar que los propósitos de las piezas van a empezar a originar unos resultados parametrizados. Dichos resultados darán pie a que se pueda entender la comunicación publicitaria de forma más lógica y clara, de manera que dependiendo del objetivo del marketing y de la planeación estratégica, se tengan claras las funciones de Carácter publicitario esperado y Efecto publicitario esperado. De esta forma la planeación publicitaria descansaría sobre una estrategia lógica que expresada en el cuadro de cualificación no daría lugar a equívocos o desviaciones, pues los pasos se darían siguiendo la estructura lógica de primeridad primera, primeridad segunda y primeridad tercera. Segundidad primera, segundidad segunda y segundidad tercera. Y terceridad primera, terceridad segunda y terceridad tercera. 
En ese orden de ideas, si un producto, bien, servicio o marca, no puede ubicarse más allá de la columna de los interpretantes inmediatos emocionales, inmediatos energéticos o inmediatos lógicos, las acciones publicitarias tendrán que ser en primeridad, es decir en términos de memorabilidad, recordación y reconocimiento. Sin embargo si la línea de la primeridad en tanto interpretantes inmediatos, se cumple, se podrá pasar a la segunda columna de interpretantes dinámicos y una vez que todos los movimientos se cumplan se podrá pasar a la tercera columna de interpretantes finales emocionales, finales energéticos y finales lógicos.

En conclusión, un análisis y evaluación de las piezas publicitarias no solamente cumpliría una función de carácter estético en el sentido de los efectos posibles que generarían las piezas, sino también de carácter ético en el sentido de las reacciones y efectos posibles y reales que se lograrían con las piezas. De igual manera, cumpliría una función de carácter lógico que estaría en el nivel del hábito encarnado, que en publicidad no es otra cosa que el Branding.

Con la puesta en marcha de lo planteado en este artículo, en acciones concretas de planeación y estrategia publicitaria, se plantea la hipótesis de una mayor efectividad en el proceso estratégico de planeación publicitaria en el ámbito del impacto, promoción y filiación propios de la publicidad. Además de ello las acciones tácticas asociadas con la creatividad publicitaria, podrán ser más certeras y eficientes, economizando tiempos y esfuerzos, redundando en mayores beneficios tanto para el anunciante como para la agencia publicitaria. 


\section{Referencias}

Brandt, L., Brandt, P. A., \& Aarhus U. (2005). Making sense of a blend: a cognitivesemiotic approach to metaphor. Aarhus: Center for Kulturforskning, Aarhus Universitet.

Groupe, $\mu$, (1992). Tratado del signo visual: para una retórica de la imagen. Madrid: Paidós.

Niño, D. (2008). El Signo peirceano y su impacto en la semiótica contemporánea. En Ensayos semióticos (Douglas Niño, ed.), 15-100. Bogotá: Universidad Jorge Tadeo Lozano.

Peirce, Ch. (1992-1997). EP. The essential Peirce. Bloomington and Indianapolis: Indiana University Press.

Peirce, Ch. (1994). CP. The Collected Papers. Cambridge: Harvard University Press. Versión electrónica en CD-ROM por InteLex Corporation.

Peirce, Ch. (1967-1971). MS. The Charles S. Peirce Papers. 32 rollos de microfilms de los manuscritos conservados en la Houghton library, Photographic Service. Cambridge, Massachussets: Harvard University Library. Disponible en www.iupui. edu/ peirce/web/robin/rcatalog.htm

Sánchez, V. (2011). La construcción del sentido publicitario: modelo de análisis y evaluación desde la perspectiva semeiótica de Charles Sanders Peirce. Recuperado de http://www.unav.es/gep/TesisDoctorales/LaConstruccionSentidoPublicitario.pdf

Short, T. (1996). Interpreting peirce's Interpretant: a response to lalor, Liszka and Meyers. En Transactions of the Charles S. Peirce Society, 32(4), 488-541.

Short, T. (2007). Peirce's Theory of Signs. Capítulo 7: Objects and Interpretants, p. 178-234-206. New York: Cambridge University Press.

Tufte, E. R. (2006). Beautiful evidence. Cheshire, Conn: Graphics Press.

Tufte, E. R. (1995). Envisioning information. Cheshire, Conn: Graphics Press.

Tufte, E. R. (1997). Visual explanations: Images and quantities, evidence and narrative. Cheshire, Conn: Graphics Press. 